\title{
Best practices for BIM Execution Plan development for a Public-Private Partnership Design-Build-Finance-Operate-Maintain project
}

\author{
J. J. McArthur \& X. Sun \\ Department of Architectural Science, Ryerson University, Canada
}

\begin{abstract}
Public-Private Partnership (P3), also known as Private Finance Initiative, projects are becoming an increasingly popular procurement method. These projects are uniquely challenging as they require the collaboration of the designers, constructors and operators from the earliest stages of the project, each of whom has a particular perspective. Balancing conflicting priorities and identifying where they align is a critical step in project planning. When BIM is used in these projects, it can provide substantial benefit to the project team by facilitating the information flow between stakeholders, minimizing duplication of effort and allowing the team to make informed decisions to optimize the project over its life cycle from both a delivery and usage perspective. A wellconceived BIM Execution Plan developed at the beginning of the project with input from all stakeholders and implemented by all stakeholders supports this goal. This approach ensures that information included in the model can be used throughout the project lifecycle, avoiding re-work, and allowing the team to "begin with the end on mind" and take full advantage of this project delivery method. This paper reviews best practices for using BIM in P3 projects and presents a framework to guide the development of a life cycle BIM execution plan applicable to this context, with the analysis and prioritization of use cases, identification of element data necessary over the project life cycle, and the staged inclusion of this data within the model. As it is based on the most complex of current project delivery methods, this framework is widely adaptable and can be used for the full range of project delivery techniques.
\end{abstract}

Keywords: BIM, BIM Execution Plan, P3, operations, project lifecycle. 


\section{Introduction}

Globally, Public-Private Partnership (P3) projects involve a partnership between the public sector (typically the end-user) and a private sector team whose members may include designers, contractors, financiers and/or facility managers. This partnership brings along several advantages, such as improved operational efficiency, minimized infrastructure deficit, and enhanced technology innovation $[1,2]$. A unique aspect of $\mathrm{P} 3$ projects is that the project is divided into two key stages: pursuit (when multiple teams prepare a preliminary design and compete to offer the lowest qualified bid), and the post-award stage, when the winning team executes the detailed design, construction and/or operations and maintenance (O\&M) of the facility.

This paper provides a framework to guide the development of Building Information Modelling (BIM) Execution Plan for the delivery of P3 projects with a particular focus on those with an O\&M component, as they emphasize the project life-cycle costs and thus the need for long-term planning from the start. This research consists of a literature review of BIM utilization and existing BIM execution plans (Section 2.1), and P3 Critical Success Factors (CSF) (Section 2.2), supported by an industry survey on P3 project delivery using BIM (Section 3) to synthesize a framework (Section 4) to guide P3 teams through the process of development or adaptation of a BIM Execution Plan that considers all phases of the project.

\section{Building an execution plan and the P3 context}

BIM has gained popularity within the Architecture, Engineering, and Construction (AEC) industry during the past decade as this developed intelligent virtual building prototype integrates graphic and nongraphic databases that can be easily retrieved during the project lifecycle, which involves the design, construction, operation and maintenance phases [3, 4]. BIM allows projects to be completed quickly and at a lower life-cycle cost because it enables significant reduction of design errors that can lead to re-work, accidents in construction, and project failures $[5,6]$.

How to adopt and optimize BIM in building construction projects remains a critical question, particularly in the operation and maintenance, though one study recommended 10 ways to engage in this phase [7]. The major challenges to BIM adoption in most companies are the lack of fully trained practitioners, and the concerns about implementation cost and potential benefits $[6,8,9]$.

\subsection{BIM Execution Plan development}

A BIM Execution Plan (BEP; or BIM Implementation Plan) is a tool to provide a standardized workflow and general guidance for strategic BIM implementation in a holistic approach for a particular project or a group of projects [10,11]. It outlines the overall project vision, defines BIM uses, and serves as a record of 
agreement among stakeholders about their roles, responsibilities, and the specific information transferring between them $[10,12,13]$. It is also recognized as a "living document" $[10,13]$ requiring constant review and updates throughout the life cycle of the project. It has been demonstrated that the early development and effective use of a BEP has a strong influence on the success of a project BIM $[10,11,14]$.

For this paper, twelve BEPs [10, 13-23] were selected of sixty in circulation, selected based on a) representation of geographical diversity, b) currency (all were published in the past five years) and c) their influence on other BEP templates $[9,24]$. As such, common elements demonstrate a best practice in BEP development. These, along with the first published BEP template [12], are presented in Figure 1.

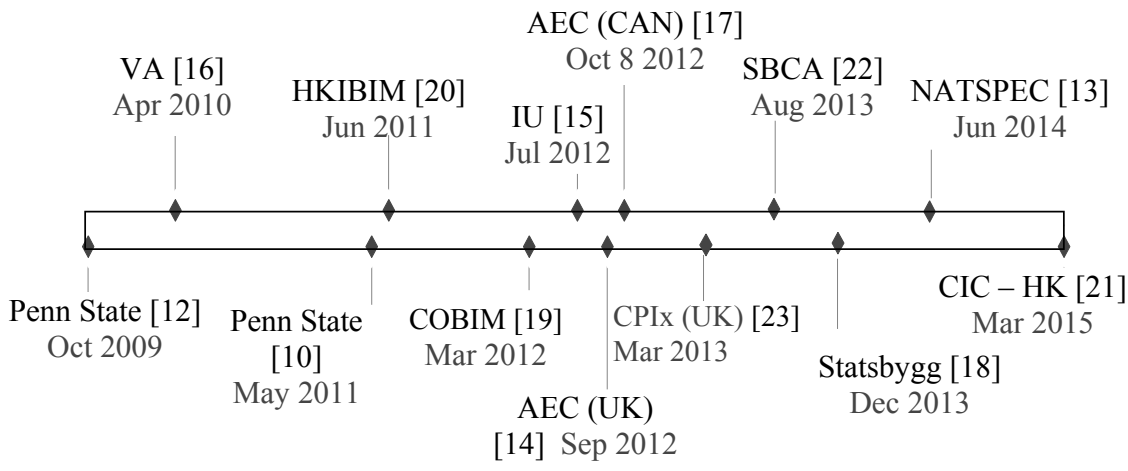

Figure 1: Timeline of BIM Execution Plan template development.

Each BEP is tailored to individual project requirements. A review of the BEP elements showed remarkable consistency across templates and the influence the original research [9] at Penn State has had on the field. These elements occurring in the majority (6 or more) of these templates have formed the core of the proposed framework, and are discussed in more detail in Section 4.

One key element, and the focus of this paper, is the selection of BIM use cases for implementation. Several were consistently included across templates as follows:

(1) Unanimous (12 of 12 templates): 3D design coordination, space management, 4D (phase) planning, engineering analysis, design authoring, building system analysis.

(2) Generally agreed (11 of 12): Design reviews, programming, maintenance scheduling, mechanical analysis, facility energy analysis, cost estimation, site analysis, structural analysis.

(3) Included by majority (9 or 10 of 12): Construction system design, existing conditions modeling, visualization, 3D construction coordination, site utilization planning, lighting analysis, code validation, sustainability evaluation. 
A series of best practices were listed explicitly in $[14,16]$ and these have been synthesized as follows and expanded to apply to the P3 context:

(1) Dedicate personnel from all partners to develop BEP (see [23]).

(2) Owner (and O\&M partner) involvement in BIM output definitions.

(3) Foster an open environment for sharing and collaboration.

(4) Develop guidelines to assist collaboration within the consortium and project stakeholders.

(5) Early planning: especially regarding use case identification and selection and phased ownership assignments for model elements.

(6) Review and update the BEP regularly and resolve outstanding issues.

(7) Provide sufficient resources for BIM [14].

(8) Ensure a consistent approach to BIM execution across all partners.

(9) All partners use standard appendices, checklist, templates, etc.

(10) Sub-divide models to avoid oversized files.

(11) Document what needs to be modeled and the Level of Development (LOD) [25] required for each element and sub-element in each phase.

(12) Modify model in 3D instead of 2D views to ensure model integrity.

\subsection{Critical Success Factors in $\mathrm{P} 3$ projects}

There has been significant research [26-29] on Critical Success Factors (CSF) required for the successful delivery of $\mathrm{P} 3$ projects, focusing primarily on project outcomes. This is complemented by recent research [30,31] differentiating the latter as "product success" and identifying additional CSF related to "project management success" and identify a number of factors contributing to efficient delivery of the product over three phases of the project: Initiation and Planning (when the project goals and requirements are determined), Procurement (including qualifying short-listed consortium, bid development (referred to in this paper as the "Pursuit Phase") and selection of the successful bidder), and Partnership (referred to herein as the "Post-Award Phase" and including detailed design, construction, operations and transfer).

Of the project management success factors summarized by [30], those potentially enabled by use of BIM include effective construction cost, time and quality management; safety management; material/resource utilization, conflict management, facility management, and interface management in P3 partnership, and life-cycle cost; and of these, effective "phase-based" evaluation are lifecycle cost are most critical to success.

\section{Survey methodology and results}

An online survey was developed based on a similar BIM use survey performed by [32], but expanded and adapted to the P3 context. This survey had a very small target population: those who had already used BIM for P3 project delivery in Canada, and to obtain the highest-quality feedback, it was designed in three sections. Part 1 (50 respondents) collected demographic and BIM experience 
data. Those with adequate experience (No. 39) proceeded to Part 2, which queried the extent of use of BIM Execution plans, perceptions of risk and their frequency of use of BIM in P3 projects. Those with too little P3 project experience (No. 15) were given an alternate set of questions regarding the barriers to this implementation, while the remainder (No. 24) proceeded to Part 3, which focused on perceived benefit and frequency of use of BIM elements, coordination roles, handover effectiveness, risk, and BIM Execution Plan use. To attract those qualified to proceed to Part 3, survey invitations were sent directly to BIM managers of firms with completed P3 projects along with the general memberships of two BIM industry associations: CANBim and buildingSMART Canada. The survey was also distributed through social media (LinkedIn and Twitter) to recruit more BIM practitioners to participate. While the total number of Part 3 respondents was relatively small, given the small population from which this sample is drawn, it is statistically significant. Of more importance, these respondents were highly experienced $(80 \%$ with $5+$ years' experience; $40 \%$ with $10+$ years), had delivered an average of six or more projects using BIM and represented a broad cross-section of consortium partners (5\% architects, $40 \%$ engineers, $10 \%$ architecture \& engineering firms, $35 \%$ general contractors and $5 \%$ subcontractors).

To identify the most beneficial use cases for P3 projects, respondents were asked to rank their perceived benefit of each in both pursuit and post-award phases. These were compared with a similar question on frequency of use, as presented in Figure 2. Not surprisingly, perceived benefit was higher post-award when detailed design, construction and/or operations were underway, but there are three outliers to this trend. Construction Coordination, Hazard Identification, and Risk Assessment were ranked more highly during pursuit. As these three are tied to schedule and risk, they have a high potential to affect the total cost of the project and may explain these results. This interpretation will be verified in follow-up interviews with the survey respondents.

Comparing frequency of BIM use cases with handover effectiveness from both design to construction and construction to operations also provided insight on use case selection. $20 \%$ of respondents reported a very effective handover from design to construction, and each of these reported that they "always" (95\% of the time) used BIM for design reviews, 3D coordination, construction simulation and construction coordination. Conversely, respondents reporting very effective handover from design to construction only occasionally $(25 \%)$, rarely $(5 \%)$ or never $(0 \%)$ used BIM for maintenance scheduling, space tracking, disaster planning, or hazard identification. Responses regarding construction to operations handover were not statistically significant for any use case.

When considering the creation of BEPs, however, several correlations arose: first, whenever the O\&M partner was typically $(75 \%+$ of the time) involved in the preparation of the BEP, respondents unanimously ranked the handover as "effective" or "very effective". Second, the involvement of both the design and construction team in the BEP development showed that in a majority of cases $(66 \%)$, handover was similarly effective from design to construction. 


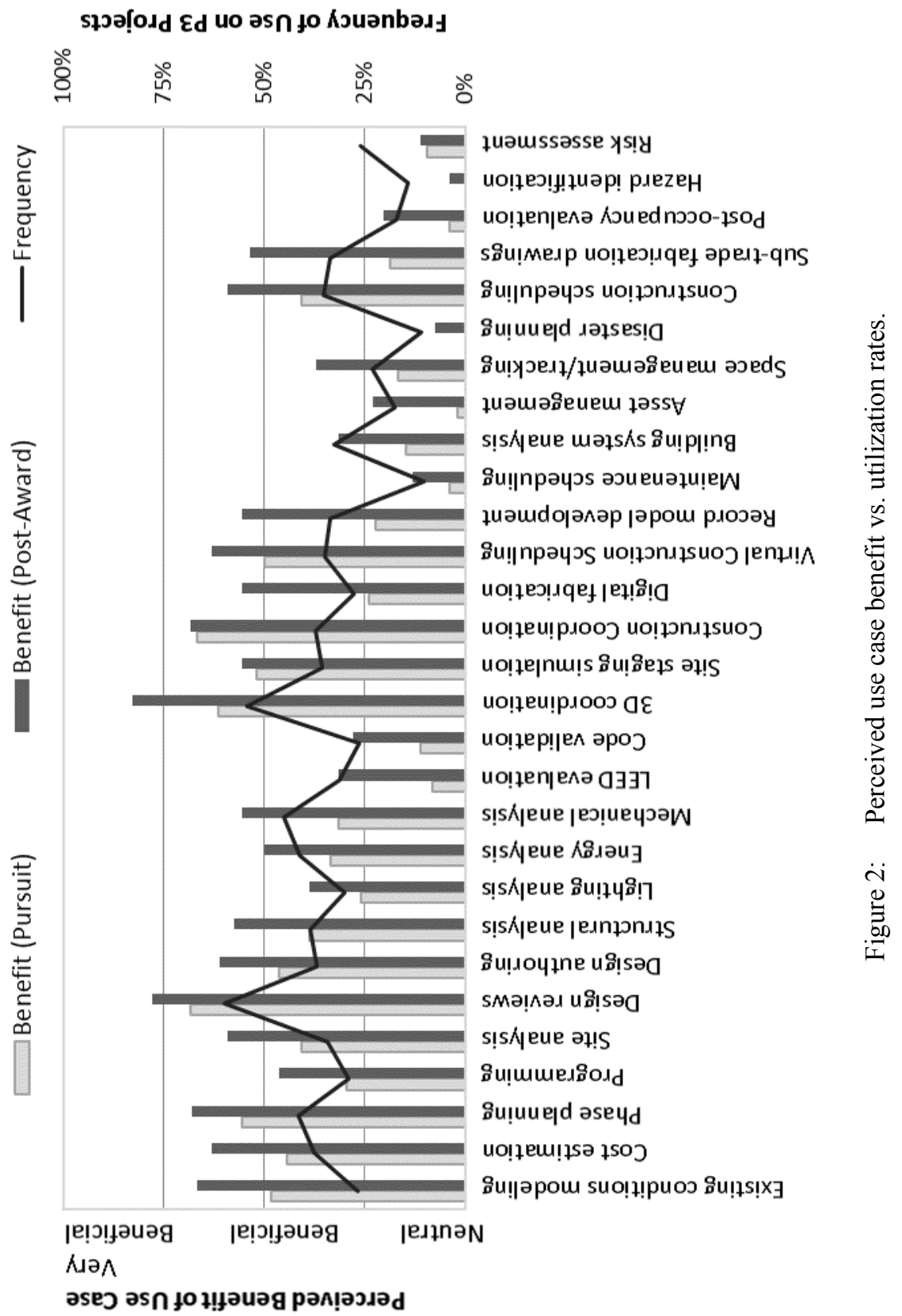




\section{BIM Execution Plan development framework}

To "begin with the end in mind", all members of the team must understand the project goals and the eventual end-uses of the BIM model in order to set it up properly to allow these end-uses. In addition to these overall project goals, short-term goals for each phase must also be determined by the team. During the pursuit stage, these focus on the submission of the lowest qualified bid (cost-effectiveness and compliance) without wasted effort (efficient delivery). After a successful bid, these extend to providing the client with the promised design at a minimum cost and schedule, again with the minimum effort required. Activities that reduce budget and schedule risk, allow for cost saving innovations, enhance coordination, improve design quality, and streamline team communication contribute to these goals. Each of these activities is supported by well-planned BIM execution, particularly with regard to the selection of value-adding use cases, identification of data required by each party, coordination and communication protocols, clear definitions of model element ownership, and model handover between phases.

To facilitate coordination, it is important to document the expected life-cycle of each building element in terms of ownership, use cases and LOD over each phase of the project, noting that each model will be eventually handed over from the designers to constructors to O\&M partners to the end-user. Element ownership can be tracked using an element ownership matrix (Table 1). In this matrix, elements (e.g. site, structure, substructure, envelope, mechanical system, etc.) and their sub-elements (e.g. substructure footings) are listed in the rows. Each is assigned an owner $(\mathbf{O})$ who is responsible for its design development and coordination with the larger project, requiring input (I) from those partners who will inherit or otherwise use or rely on the element, and flagged to make those who would be affected aware (A) of by changes to the element. The model elements include. An example of sub-elements could be ductwork and pipework under mechanical system.

Table 1: Element ownership matrix.

\begin{tabular}{llllllllll}
\hline & A & S & M & E & C & GC & SC() & O\&M & etc... \\
\hline Model Element 1 & & & & & & & & & \\
\hline Sub-element 1 & I & O & A & & A & I & I & A & \\
\hline Sub-element 2 & I & O & A & A & A & I & I & A & \\
\hline Etc... & I & I & I & & O & I & I & I & A \\
\hline S & &
\end{tabular}

A=architect, $S=$ Struct. Eng., M=Mech. Eng., E=Elec. Eng., C=Civil Eng., $G C=$ general contractor, $S C()=$ sub-contractor(specify); $O \& M=$ facility manager, etc... 
Table 2 provides the proposed BEP framework (based on [10], defining each individual BEP element, while the BIM process map indicated in Figure 3 provides an illustration of how these BEP elements are used to support the project goals. Given the accelerated schedule and tight budget typical of P3 projects, it is critical that re-work is kept to a minimum throughout the design

Table 2: BIM Execution Plan framework.

\begin{tabular}{|c|c|}
\hline Element & Description \\
\hline BEP overview & $\begin{array}{l}\text { Describes purpose of the BEP and who is involved in } \\
\text { developing and revising it. Survey results indicate that input } \\
\text { from design, construction, and O\&M partners are correlated } \\
\text { with efficient model and project handover. }\end{array}$ \\
\hline $\begin{array}{l}\text { Project } \\
\text { information }\end{array}$ & $\begin{array}{l}\text { Project number, project name, client name, project location, } \\
\text { critical milestones, and project schedule. }\end{array}$ \\
\hline $\begin{array}{l}\text { Project } \\
\text { deliverables }\end{array}$ & $\begin{array}{l}\text { Define the project deliverables and key metrics to define project } \\
\text { success including links to compliance documents and project } \\
\text { requirements }\end{array}$ \\
\hline Project goals & Defines project goals during each project phase \\
\hline $\begin{array}{l}\text { Key team and } \\
\text { project contacts }\end{array}$ & $\begin{array}{l}\text { Project manager, BIM manager, and discipline leads for } \\
\text { architectural, structural, and MEP design, other consultants, } \\
\text { general contractors, sub-constructors, and facility manager }\end{array}$ \\
\hline $\begin{array}{l}\text { Organizational } \\
\text { roles }\end{array}$ & $\begin{array}{l}\text { Develop an organizational chart for all personnel involved with } \\
\text { the BIM models, whether in an "own", "input" or "aware" role } \\
\text { (refer to Table 1) }\end{array}$ \\
\hline $\begin{array}{l}\text { BIM process } \\
\text { diagram }\end{array}$ & $\begin{array}{l}\text { Visual representation of how BIM will be used throughout the } \\
\text { process (e.g. Figure } 3 \text { ) }\end{array}$ \\
\hline $\begin{array}{l}\text { Technology } \\
\text { infrastructure }\end{array}$ & $\begin{array}{l}\text { Identify software to be used, hardware requirements and } \\
\text { network/cloud connectivity to facilitate model sharing and } \\
\text { handover }\end{array}$ \\
\hline Model structure & $\begin{array}{l}\text { Define model components or multiple models (e.g. architectural, } \\
\text { structural, MEP, fabrication) and how they will interface with } \\
\text { one another }\end{array}$ \\
\hline $\begin{array}{l}\text { Collaboration } \\
\text { procedures }\end{array}$ & $\begin{array}{l}\text { Define model management procedures, e.g. file structures, } \\
\text { permissions, model upload and information exchange schedule } \\
\text { if not centrally hosted }\end{array}$ \\
\hline $\begin{array}{l}\text { BIM and facility } \\
\text { data } \\
\text { requirements }\end{array}$ & $\begin{array}{l}\text { Identify } 3^{\text {rd }} \text { party data required for BIM (inputs) and end-user } \\
\text { (owner/O\&M partner) data management systems (outputs) to } \\
\text { ensure compatibility }\end{array}$ \\
\hline $\begin{array}{l}\text { BIM information } \\
\text { exchanges }\end{array}$ & $\begin{array}{l}\text { Define level of detail for each component at handover and any } \\
\text { information exchange standards (e.g. Construction Operations } \\
\text { Building information exchange (COBie, [33]) being used and } \\
\text { required interfaces with } 3^{\text {rd }} \text { party software (analysis, fabrication } \\
\text { or operations) }\end{array}$ \\
\hline BIM uses* & $\begin{array}{l}\text { Identify the most beneficial use cases for this phase (refer to } \\
\text { Figure 2) and additional data/information and BIM LOD } \\
\text { required to implement each }\end{array}$ \\
\hline $\begin{array}{l}\text { Model quality } \\
\text { control }^{*}\end{array}$ & $\begin{array}{l}\text { Defines ongoing model quality control procedures, e.g. design } \\
\text { review scope and frequency, clash detection, etc. }\end{array}$ \\
\hline
\end{tabular}

${ }^{*}$ Repeated at each phase. 


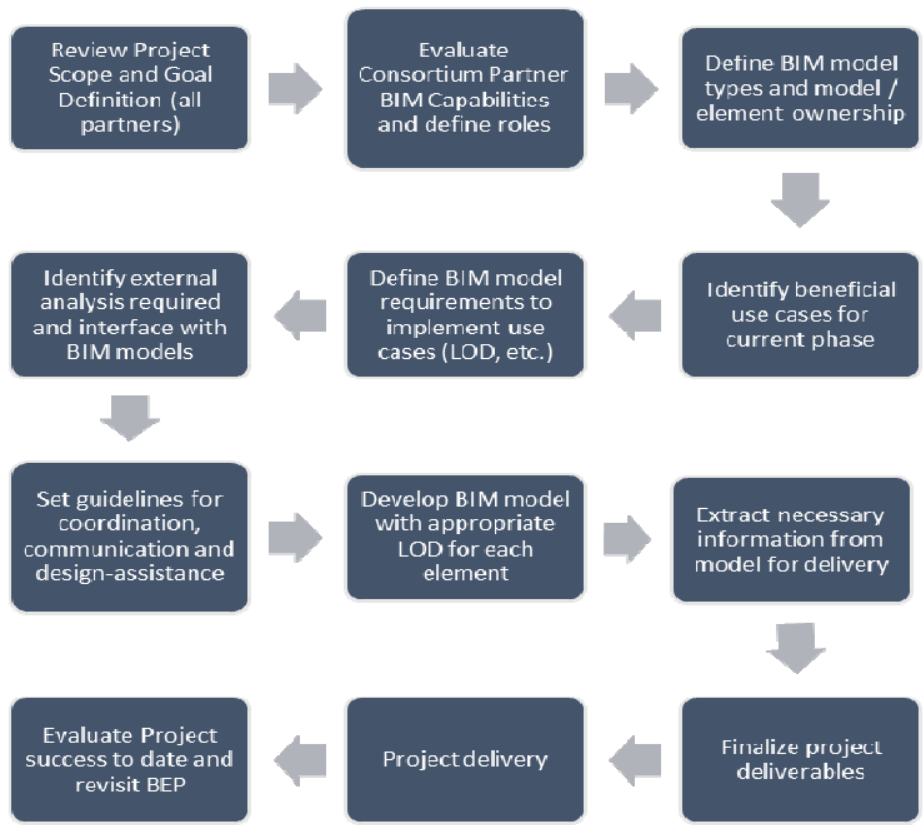

Figure 3: BIM process diagram.

and construction process. One way to minimize re-work is to stage the inclusion of data in the model. This is done by limiting the LOD of BIM elements while the potential for change to that element is high. Curves showing the relative potential for an element to change over the project and the corresponding recommended LOD for that element are indicated in Figure 4. While some

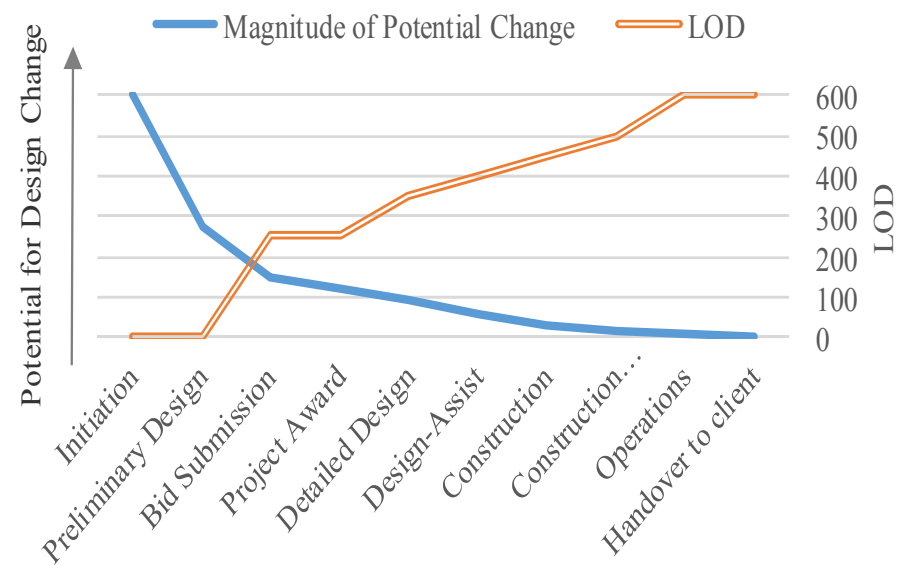

Figure 4: BIM LOD as a function of potential for design change. 
geometry must be modelled accurately at early stages (e.g. room layouts) to resolve the design quickly, many elements (particularly service distribution) can be represented conceptually in BIM (LOD 100) or modelled with approximate geometry (LOD 200) until the rate of design change slows. Identifying those elements requiring higher levels of development (LOD 300+) because of their effect on other systems is a critical step in developing the BIM Execution Plan, and a LOD matrix should be created reflecting each phase, containing the elements and sub-elements in rows and the LOD for each phase in columns.

\section{Recommendations and conclusions}

$\mathrm{BIM}$ is a recognized tool to facilitate improved communication and coordination among a distributed project team such as a consortium bidding on and delivering a P3 project. Given the budget constraints need for an accelerated schedule, it is critical that BIM be used as efficiently as possible in these projects.

Using BIM to extend building models beyond 3D, implementing cost estimation, construction scheduling and engineering analysis, the design and construction processes can be streamlined and delivery efficiency improved. To take best advantage of this tool, teams need to identify those use cases most appropriate for their projects and within their capabilities to properly deliver. Early identification of these use cases, informed by the normative literature (Section 2.1) and survey results (Figure 2) included herein, allow teams to plan the BIM execution to facilitate these use cases and identify the necessary information and interfaces required.

The involvement of both design and construction personnel improved the handover effectiveness from design to construction, and similarly the involvement of involved the O\&M partner in the BEP development for projects improved the handover effectiveness from construction to operations, and the ongoing participation of these members in the BEP development is critical to optimizing project success.

This paper has proposed a BIM Execution Plan development framework outlining key elements required to support P3 project delivery, supplemented by a representative BIM Process diagram, an ownership matrix and recommendations for the staged inclusion of data in the BIM model. This framework is intended to assist companies with the development or modification of BIM execution plans specifically for P3 project delivery in an efficient manner.

\section{Acknowledgements}

The authors would like to thank the Canada BIM Council (CanBIM) and buildingSMART Canada (bSC) for their assistance with survey dissemination. 


\section{References}

[1] Chan, A., Chan, D. \& Ho, K., An empirical study of the benefits of construction partnering in Hong Kong. Construction Management and Economics, 21(5), pp. 523-533, 2003.

[2] Hwang, B., Zhao, X. \& Gay, M., Public private partnership projects in Singapore: Factors critical risks and preferred risk allocation from the perspective of contractors. International Journal of Project Management, 31(3), pp. 424-433, 2013.

[3] Becerik-Gerber, B. \& Kensek, K., Building information in architecture, engineering, and construction: Emerging research directions and trends. Journal of Professional Issues in Engineering Education and Practice, 136(3), pp. 139-147, 2010.

[4] Love, P.E.D., Matthews, J., Simpson, I., Hill, A. \& Olatunji, O.A., A benefits realization management building information modeling framework for asset owners. Automation in Construction, 37(2014), pp. 110, 2014.

[5] Love, P.E.D., Edwards, D.J., Han S. \& Goh Y.M., Design error reduction: Toward the effective utilization of building information modeling. Research in Engineering Design, 22(3), pp. 173-187, 2011.

[6] Bryde, D., Broquetas, M. \& Volm, J. M., The project benefits of building information modeling (BIM). International Journal of Project Management, 31(7), pp. 971-980, 2013.

[7] Mohandes, S.R., Preece, C. \& Hedayati, A., Exploiting the effectiveness of building information modeling during the stage of post construction. Journal of Basic and Applied Scientific Research, 4(10), pp. 5-16, 2014.

[8] Hardin, B., BIM and Construction Management Proven Tools, Methods, and Workflows, Indiana: Wiley Publishing, 2009.

[9] Ahmad, A.M., Demian, P. \& Price, A.D.F. BIM implementation plans: A comparative analysis. In: Smith, D. D. (ed.) Proceedings 28th Annual ARCOM Conference. Association of Researchers in Construction Management, pp. 33-42, 2012.

[10] Computer Integrated Construction (CIC) Research Program. BIM Project Execution Planning Guide - Version 2.1. Pennsylvania State University, University Park, PA, USA, 2011.

[11] Wu, W. \& Issa, R.R.A., BIM execution planning in green building projects: LEED as a used case. Journal of Management in Engineering, 31(Special issue), 2015.

[12] Saluja, C., A process mapping procedure for planning building information modeling (BIM) execution on a building construction project (Master Thesis, Pennsylvania State University), 2009.

[13] NATSPEC. NATSPEC BIM management plan template (v1.0), 2012.

[14] AEC (UK) Initiative. AEC (UK) BIM protocol - project BIM execution plan (version 2.0), 2012.

[15] Indiana University Architect's Office, BIM guidelines \& standards for architects, engineers, and contractors, 2012. 
[16] Department of Veterans Affairs, The VA BIM guide, 2012.

[17] CanBIM, AEC (CAN) BIM protocol, 2012.

[18] Statsbygg, Building Information Modeling Manual (v.1.2.1), 2013.

[19] COBIM. Common BIM requirements, Finland, 2012.

[20] Hong Kong Institute of Building Information Modeling (HKIBIM), HKIBIM BIM standard - BIM project specification.

[21] Construction Industry Council - HK, CIC building information modeling standards Draft 6.0, 2015.

[22] Singapore Building and Construction Authority (SBCA), Singapore BIM guide (version 2), 2013.

[23] Construction Project Information Committee (UK), Post Contract-Award Building Information Modelling (BIM) Execution Plan (BEP), 2013.

[24] Hooper, M., BIM Anatomy: an investigation into implementing prerequisites, 2011.

[25] American Institute of Architects. E202-2008 Building Information Modeling Protocol, 2008.

[26] Osei-Kyei, R. \& Chan, A., Review of studies on the critical success factors for public-private partnership (PPP) projects from 1990 to 2013. Int. J. Proj. Manag., doi: 10.1016/j.ijproman.2015.02.008, 2015.

[27] Chan, W., Chen, C., Messner, J. \& Chua, D., Interface management for China's build-operate-transfer projects. Journal of Construction Engineering and Management, 131(6), pp. 645-655, 2005.

[28] Aziz, A., Successful delivery of public-private partnerships for infrastructure development. Journal of Construction Engineering and Management, 133(12), pp. 918-931, 2007.

[29] Jacobson, C. \& Choi, S.O., Success factors: public works and publicprivate partnerships. International Journal of Public Sector Management, 21(6), pp. 637-657, 2008.

[30] Liu, J., Love, P.E.D, Smith, J., Regan, M. \& Davis, P.R., Life cycle critical success factors for public-private partnership infrastructure projects. Journal of Management in Engineering, 10.1061/(ASCE) ME.1943-5479.0000307, 04014073, 2014.

[31] Liu, J., Love, P.E.D., Davis, P.R., Smith, J. \& Regan, M., Conceptual framework for the performance measurement of public-private partnerships. Journal of Infrastructure Systems, 21(1), 04014023, 2015.

[32] Kreider, R., Messner, J. \& Dubler, C., Determining the frequency and impact of applying BIM for different purposes on projects. Proceedings $6^{\text {th }}$ International Conference on Innovation in Architecture, Engineering and Construction (AEC), Pennsylvania State University, University Park, PA, USA, 2010.

[33] Anderson, A., Marsters, A., Dossick, C. \& Neff, G., Construction to operation exchange: Challenges of implementing COBie and BIM in a large owner organization. Construction Research Congress 2012, pp. 688-697, 2012. 